\title{
Retraction Note: Vibrio parahaemolyticus RhsP represents a widespread group of pro-effectors for type $\mathrm{VI}$ secretion systems
}

\author{
Nan Jiang ${ }^{1}$, Le Tang ${ }^{2,3,4}$, Ruiqiang Xie ${ }^{1}$, Zhi Li ${ }^{1}$, Brianne Burkinshaw ${ }^{2,3,4}$, Xiaoye Liang ${ }^{5}$, Dylan Sosa ${ }^{6}$, L. Aravind ${ }^{7}$, \\ Tao Dong (10) 2,3,4,5, Dapeng Zhang6,8 \& Jun Zheng (1) ${ }^{1}$
}

Retraction to: Nature Communications; https://doi.org/10.1038/s41467-018-06201-5; published online 25 Sep 2018

In this Article, we reported that, in Vibrio parahaemolyticus, secretion of protein RhsP by a Type VI secretion system requires removal of an N-terminal fragment by auto-proteolysis, followed by interaction with a PAAR protein.

However, it has come to our attention that parts of the experimental data reported in the paper were a result of image manipulation. Specifically, western blot images presented in Figs. 2e, 3a, 3b and 4c, and Supplementary Figs. 3a, 3b and 10, were subjected to manipulation including band duplication and rotation, cutting and pasting of bands into gels, and band elimination.

In light of these findings, we cannot be confident of the conclusions of the paper as it stands. We therefore wish to retract the paper. We deeply regret these circumstances and apologize to the scientific community. All authors agree with retraction of the Article.

Published online: 15 March 2019

\begin{abstract}
(c) (i) Open Access This article is licensed under a Creative Commons Attribution 4.0 International License, which permits use, sharing, adaptation, distribution and reproduction in any medium or format, as long as you give appropriate credit to the original author(s) and the source, provide a link to the Creative Commons license, and indicate if changes were made. The images or other third party material in this article are included in the article's Creative Commons license, unless indicated otherwise in a credit line to the material. If material is not included in the article's Creative Commons license and your intended use is not permitted by statutory regulation or exceeds the permitted use, you will need to obtain permission directly from the copyright holder. To view a copy of this license, visit http://creativecommons.org/licenses/by/4.0/.
\end{abstract}

(c) The Author(s) 2019

\footnotetext{
${ }^{1}$ Faculty of Health Sciences, University of Macau, Macau SAR, China. ${ }^{2}$ Department of Ecosystem and Public Health, University of Calgary, Calgary, AB T2N 4Z6, Canada. ${ }^{3}$ Department of Biochemistry and Molecular Biology, University of Calgary, Calgary, AB T2N 4Z6, Canada. ${ }^{4}$ Snyder Institute for Chronic Diseases, University of Calgary, Calgary, AB T2N 4Z6, Canada. ${ }^{5}$ State Key Laboratory of Microbial Metabolism, Joint International Laboratory on Metabolic and Developmental Sciences, School of Life Sciences and Biotechnology, Shanghai Jiao Tong University, Shanghai 200240, China. ${ }^{6}$ Program of Bioinformatics and Computational Biology, College of Arts and Sciences, Saint Louis University, Saint Louis, MO 63103, USA. ${ }^{7}$ National Center for Biotechnology Information, National Library of Medicine, National Institutes of Health, Bethesda, MD 20894, USA. ${ }^{8}$ Department of Biology, College of Arts and Sciences, Saint Louis University, Saint Louis, MO 63103, USA. These authors contributed equally: Nan Jiang, Le Tang. Correspondence and requests for materials should be addressed to T.D. (email: tdong@ucalgary.ca) or to D.Z. (email: dapeng.zhang@slu.edu) or to J.Z. (email: junzheng@umac.mo)
} 